\title{
Processing of submicron grain 304 stainless steel
}

\author{
M. Jain and T. Christman ${ }^{\text {a) }}$ \\ W. M. Keck Laboratory of Engineering Materials, California Institute of Technology, \\ Pasadena, California 91125
}

(Received 20 May 1995; accepted 10 July 1996)

A novel thermomechanical processing technique for the synthesis of bulk submicron grain (grain size $\approx 200 \mathrm{~nm}$ ) 304 stainless steel is reported. This ingot-metallurgical technique requires a total deformation of only $95 \%$, and the key steps to this processing technique involve (i) formation of ultrafine dislocation cell structure, and (ii) the conversion of dislocation cells into grains with medium to high misorientation by grain boundary sliding.

Materials with submicron grain microstructure exhibit significantly improved mechanical properties over their course grain counterparts. ${ }^{1}$ These properties include higher strength, improved formability and ductility, and reduced superplastic temperature. ${ }^{2}$ However, due to metastable nature of these microstructures, submicron grain materials are difficult to produce in bulk form and are usually produced by special powder metallurgical techniques. ${ }^{3,4}$

There is a considerable interest in nonpowder metallurgical techniques for the production of these materials, because the problem of residual porosity can be completely avoided by the use of these techniques. ${ }^{1}$ Here, we describe a novel processing technique for the production of a submicron grain $(200 \mathrm{~nm}) 304$ stainless steel (304 SS) by an ingot metallurgical route. This processing technique does not require any powder precursors and requires a total deformation of only $95 \%$. The key steps to this technique involve (i) generation of a dislocation cell structure of same size (or finer) to finally desired grain size, and (ii) activation of grain boundary sliding in this microstructure, leading to conversion of dislocation cells into grains with high angle boundaries. This processing technique is based on our previous work where we observed the collapse of microstructure in $\mathrm{Fe}-28 \mathrm{Al}-2 \mathrm{Cr}$ intermetallic compound from $80 \mathrm{~nm}$ to $10 \mathrm{~nm}$ during room temperature compressive deformation. ${ }^{4}$

The starting material for this investigation was a commercial grade 304 stainless steel (304 SS) with an average grain size of $\approx 200 \mu \mathrm{m}$. The $\mathrm{x}$-ray diffraction (XRD) pattern of the as-received stainless steel is shown in Fig. 1. The microstructure consists of a mixture of bcc

\footnotetext{
a)Present address: Gillette R\&D, Gillette Park, Boston, Massachusetts 02106-2131.
}

and fcc phases as peaks from both bcc and fcc phases are visible in the $\mathrm{x}$-ray diffraction pattern.

The 304 SS rod (3/8" in diam) was initially rolled $63 \%$ at room temperature to an ingot with square cross section. This ingot was further rolled $65 \%$ at liquid nitrogen temperature, which resulted in reduction of cross section to 0.120 in. $\times 0.120$ in. The ingot obtained in this manner will be referred to as SS8 in the rest of this paper.

The microstructure of the SS8 ingot was examined by transmission electron microscopy (TEM) and x-ray diffraction in both directions, i.e., in the planes parallel and perpendicular to the axis of rolling. X-ray diffraction scan of this ingot as shown in Fig. 1 reveals that the microstructure consists entirely of bcc phase. The microstructure of SS8 ingot as examined by TEM is shown in Fig. 2. The microstructure has a lath morphology, which is quite typical of phases formed by martensitic phase transformations. Furthermore, the morphology of microstructure is approximately the same in both directions, i.e., in the planes perpendicular and parallel to the axis of rolling. The martensite phase is extremely fine with laths ranging from $50-100 \mathrm{~nm}$ in width and 500-1000 $\mathrm{nm}$ in length.

The SS8 ingot was then annealed at $575{ }^{\circ} \mathrm{C}$ for $2 \mathrm{~h}$. The microstructure in this state was also examined by TEM in the plane parallel as well as perpendicular to the axis of rolling. The microstructure consists of long columnar grains mostly aligned parallel to the axis of rolling. In addition, these columnar grains contain equiaxed cellular structure with sharp cell boundaries. The size of the cells ranges from 100-300 nm, and the average cell size is $\approx 200 \mathrm{~nm}$. A typical microstructure is shown in Fig. 3. A selected area diffraction (SAD) pattern from this sample with an aperture area of $0.75 \mu \mathrm{m}^{2}$ is also shown in Fig. 3. 


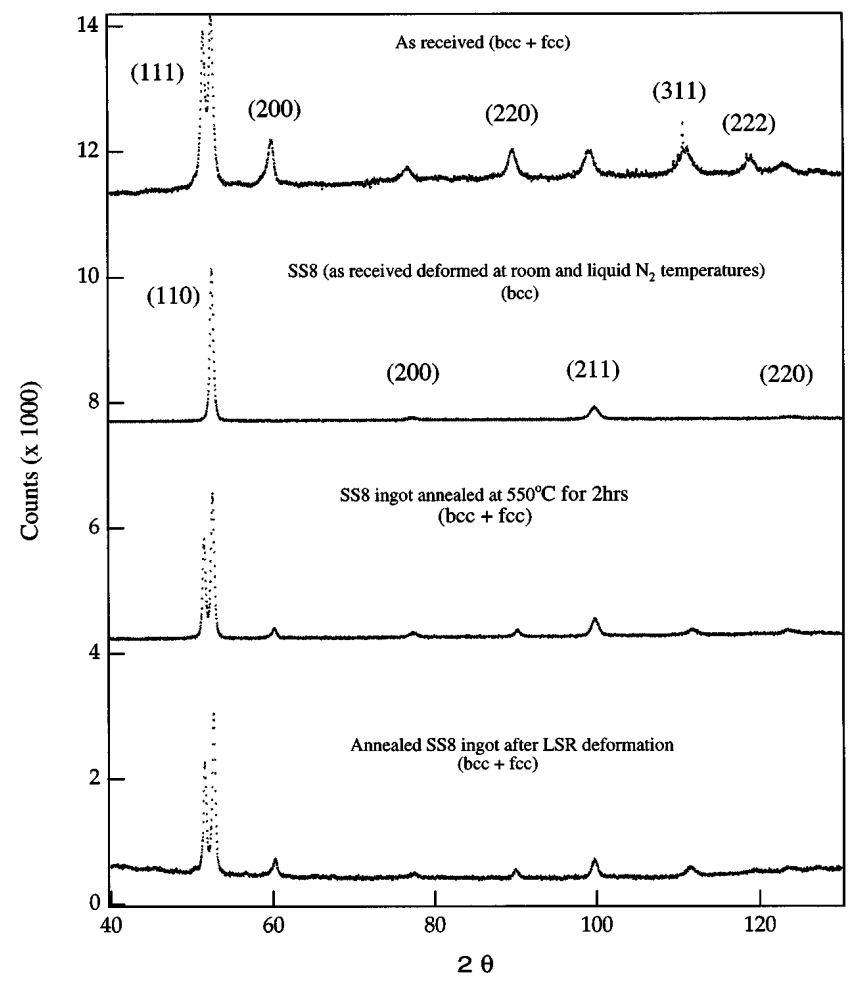

FIG. 1. X-ray diffraction pattern of 304 stainless steel in as-received condition, after deformation at room and liquid nitrogen temperature, after annealing at $575{ }^{\circ} \mathrm{C}$ for $2 \mathrm{~h}$ and after LSR deformation on annealed SS8 ingot.

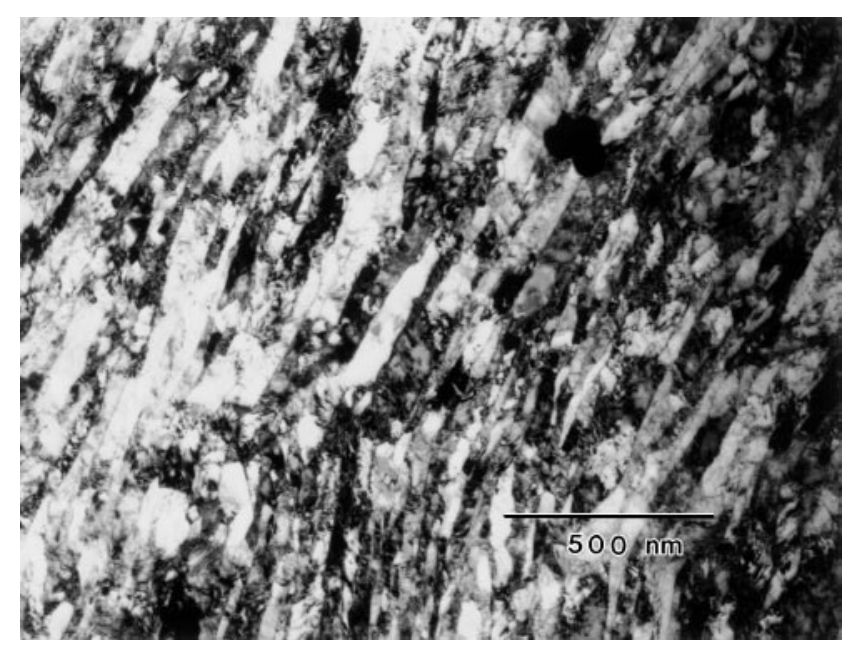

FIG. 2. Microstructure (BF image) of 304 stainless steel rolled 63\% at room temperature and $65 \%$ at liquid nitrogen temperature. The microstructure has lath morphology and consists entirely of bcc phase.

Several nearly cubical samples $(\approx 2.6 \mathrm{~mm})$ were cut out of the annealed SS8 ingot for compression testing. These samples were deformed in compression (opposite to the direction of rolling) at temperatures ranging from $24{ }^{\circ} \mathrm{C}$ (room temperature) to $575{ }^{\circ} \mathrm{C}$ at the crosshead speed of $0.0002 \mathrm{in} . / \mathrm{min}$. This corresponded to a nominal strain rate of $4.4 \times 10^{-5} \mathrm{~s}^{-1}$. A flow stress
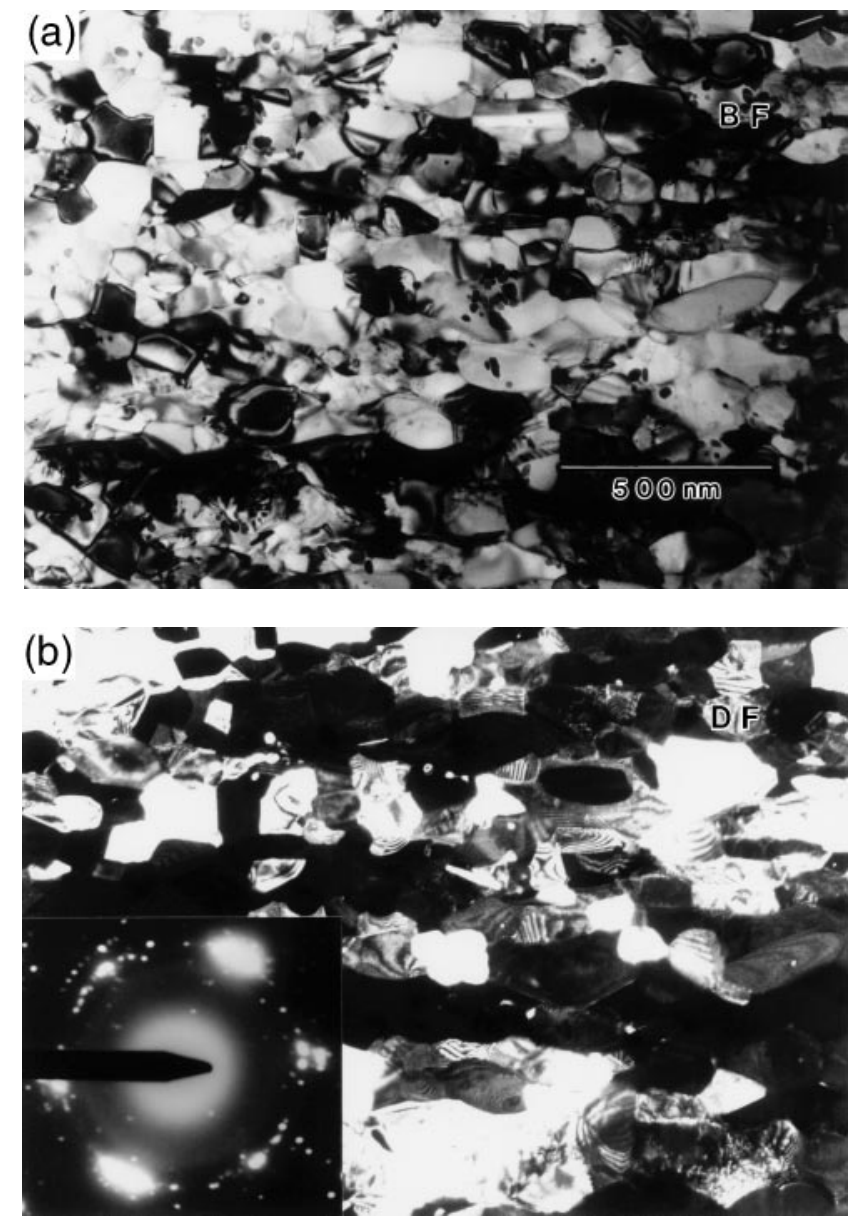

FIG. 3. Microstructure (in the plane parallel to the axis of rolling) of the SS8 ingot annealed at $575{ }^{\circ} \mathrm{C}$ for $2 \mathrm{~h}$ : (a) BF and (b) DF. The columnar grains are aligned parallel to the axis of rolling and contain equiaxed cellular structure.

versus deformation temperature plot for the annealed SS8 ingot at temperatures ranging from $24{ }^{\circ} \mathrm{C}$ to $575{ }^{\circ} \mathrm{C}$ is shown in Fig. 4. The flow stress decreases very slowly from room temperature to about $500{ }^{\circ} \mathrm{C}$ and decreases abruptly thereafter.

The microstructures after the LSR deformation were examined by TEM in both directions, i.e., in the planes perpendicular as well as parallel to the axis of rolling. Note that the LSR deformation was carried out opposite to the direction of rolling deformation. The microstructure of the sample deformed at $450{ }^{\circ} \mathrm{C}$ was very similar to that prior to LSR deformation. It consisted of columnar grains aligned parallel to the axis of rolling. However, the microstructure of sample deformed at $550{ }^{\circ} \mathrm{C}$ consisted of equiaxed grains (average grain size of $\approx 200 \mathrm{~nm}$ ) with low dislocation density. The representative microstructure of the annealed SS8 sample deformed at $550{ }^{\circ} \mathrm{C}$ and the crosshead speed of $0.0002 \mathrm{in} . / \mathrm{min}$ (nominal strain rate $4.4 \times 10^{-5} \mathrm{~s}^{-1}$ ) is shown in Fig. 5. A SAD pattern from this sample with 


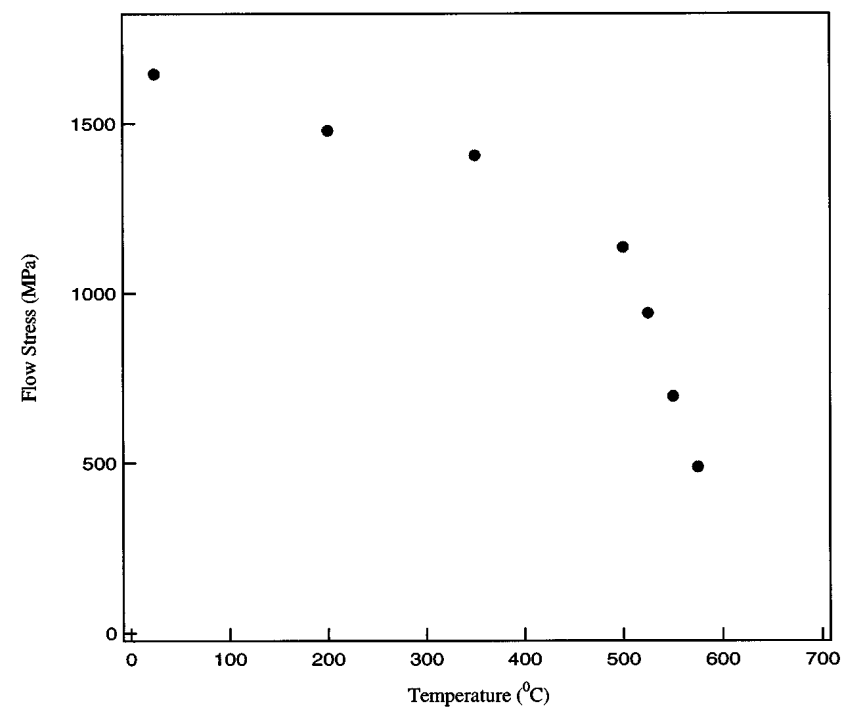

FIG. 4. Flow stress versus temperature curve for annealed SS8 ingot deformed at the nominal strain rate of $4.4 \times 10^{-5} \mathrm{~s}^{-1}$. Note that the flow stress drops abruptly after $500{ }^{\circ} \mathrm{C}$.

an aperture area of $0.75 \mu \mathrm{m}^{2}$ is also shown in Fig. 5 . The innermost (diffuse) ring in the SAD pattern is an artefact due to the aperture and should be ignored. The diffraction rings in this SAD pattern are significantly more uniform than their counterpart rings in Fig. 3.

The XRD patterns before and after LSR deformation at $550{ }^{\circ} \mathrm{C}$ are very similar to each other (Fig. 1). This suggests that no significant phase transformation takes place during LSR deformation.

The formation of submicron grain microstructure with an average grain size of $200 \mathrm{~nm}$ in bulk $304 \mathrm{SS}$ is evident from the dark field (DF) image and SAD pattern in Fig. 5. The relative uniformity of the diffraction rings in the SAD pattern (aperture area approximately $0.75 \mu \mathrm{m}^{2}$ ) after LSR deformation suggests that the misorientation among the grains is large and that the grain boundaries are medium to high angle grain boundaries. The starting material for this processing technique is 304 stainless steel with a grain size of $200 \mu \mathrm{m}$, and this processing technique requires a total strain of only $94 \%$. The processing of submicron grain 304 stainless steel can be divided into two parts: (i) formation of submicron columnar grains with equiaxed cellular structure, and (ii) break up of columnar grains and conversion of dislocation cells into grains with medium to high angle grain boundaries.

The first step in the processing of ultrafine grain 304SS involves deformation of the steel ingot in asreceived condition (average grain size $\approx 200 \mu \mathrm{m}$ ) at room and liquid nitrogen temperature. This results in martensitic transformation of fcc phase into an ultrafine bcc phase. Following the martensitic transformation, the ingot was annealed at $575{ }^{\circ} \mathrm{C}$ for $2 \mathrm{~h}$. This results
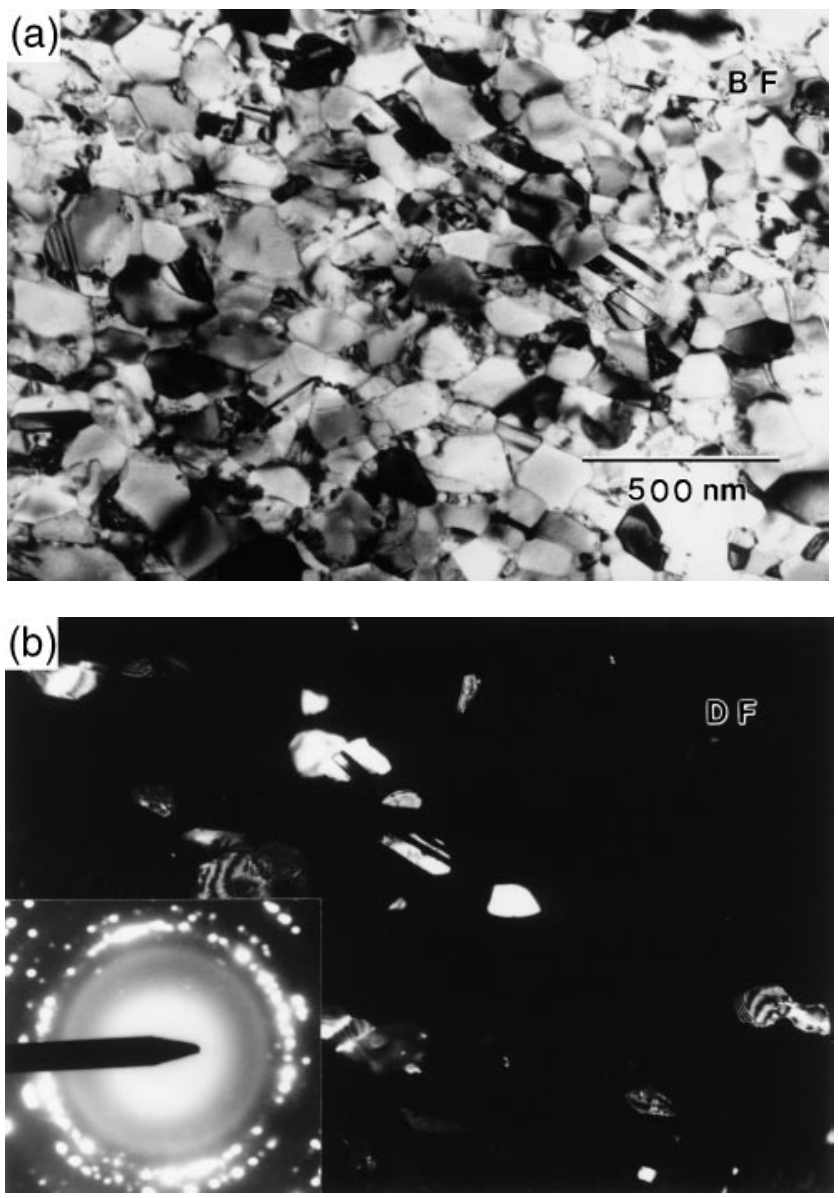

FIG. 5. Microstructure (in the plane parallel to the axis of rolling) of the annealed SS8 ingot deformed at $550{ }^{\circ} \mathrm{C}$ and nominal strain rate of $4.4 \times 10^{-5} \mathrm{~s}^{-1}$ : (a) BF and (b) DF. Note the equiaxed grains and low defect density in the microstructure. The innermost (diffuse) ring in the SAD pattern is an artefact due to the aperture and should be ignored.

in partial reversion of bcc phase into fcc phase. The microstructure morphology after this annealing treatment consists of columnar grains $\approx 200 \mathrm{~nm}$ in diameter and about 1000-2000 nm in length. Furthermore, these columnar grains contain equiaxed subgrains approximately $200 \mathrm{~nm}$ in size.

Clearly the ultrafine morphology of bcc phase formed by deformation at liquid $\mathrm{N}_{2}$ temperature is critical to formation of ultrafine cellular structure. Note that the smallest dimension of the bcc laths (thickness) was smaller than the cellular structure formed after annealing at $575{ }^{\circ} \mathrm{C}$.

The precipitous drop in flow stress of annealed SS8 ingot (at nominal strain rate of $4.4 \times 10^{-5} \mathrm{~s}^{-1}$ ) with temperature, starting at $500{ }^{\circ} \mathrm{C}$ (Fig. 4) suggests a change in deformation mechanism at this temperature. This is further corroborated by the observation that the microstructure of annealed SS8 ingot after LSR deformation at $450{ }^{\circ} \mathrm{C}$ is substantially different 
from that deformed at $550{ }^{\circ} \mathrm{C}$. The microstructure of the sample deformed at $450{ }^{\circ} \mathrm{C}$ consisted of columnar grains aligned parallel to the axis of rolling, while the microstructure of sample deformed at $550{ }^{\circ} \mathrm{C}$ consists of equiaxed grains (average grain size of $\approx 200 \mathrm{~nm}$ ) with low dislocation density.

The microstructure of annealed SS8 ingot changes substantially after the low strain rate deformation (opposite to the direction of rolling deformation) at $550{ }^{\circ} \mathrm{C}$. The transformed microstructure consists primarily of equiaxed ultrafine grains (grain size $\approx 200 \mathrm{~nm}$ ). Furthermore, the grains after LSR deformation are very similar in size to cells before LSR deformation, and the rings in the SAD pattern after LSR deformation are relatively uniform compared to those prior to deformation. This indicates that misorientation among the cells has increased during LSR deformation. All these observations suggest that grain boundary sliding is the operating deformation mechanism during LSR deformation. Grain boundary sliding results in rotation and translation of grains (in present case, dislocation cells) with respect to each other, and interchange of neighbors. ${ }^{5-7}$ This process causes misorientation among the cells to increase and results in conversion of dislocation cells into grains with medium to high angle grain boundaries during LSR deformation. Tsuzaki et al. have observed similar behavior in $25 \mathrm{Cr}-7 \mathrm{Ni}-3 \mathrm{Mo}$ ferrite/austenite duplex steel at $1000{ }^{\circ} \mathrm{C} .{ }^{8}$

An ultrafine grain microstructure (grain size $\approx 200 \mathrm{~nm}$ ) can be formed in bulk 304 stainless by a deformation-based processing technique that does not require powder precursors. In addition, this processing requires only $95 \%(e=3)$ total strain and is amenable to scale up. This is in comparison to large strains $(e=7)$ required by other processing techniques. ${ }^{9-11}$
The first step of this two-step processing technique requires deformation at room and liquid nitrogen temperature followed by annealing at $575{ }^{\circ} \mathrm{C}$. This treatment results in the formation of an equiaxed dislocation cell structure encased in columnar grains aligned parallel to the axis of rolling. The final step involves deformation at low strain rate (nominal strain rate $4.4 \times 10^{-5} \mathrm{~s}^{-1}$ ) and high temperature $\left(550{ }^{\circ} \mathrm{C}\right)$. This results in conversion of columnar grain microstructure into equiaxed grain microstructure (grain size $\approx 200 \mathrm{~nm}$ ). Activation of grain boundary sliding appears to the primary cause of this transition.

\section{ACKNOWLEDGMENTS}

We gratefully acknowledge the National Science Foundation for supporting this research through Grant Nos. DMR-9116570 and DMR-9396132; Program Director: Dr. B. MacDonald. The authors are also thankful to Professor G. Ravichandran and Professor T. Vreeland for several valuable discussions.

\section{REFERENCES}

1. R. Z. Valiev, N. A. Krasilnikov, and N. K. Tsenev, Mater. Sci. Engng. A137, 35 (1991).

2. D. R. Lesuer, C. K. Syn, A. Goldberg, J. Wadsworth, and O. D. Sherby, J. Metals 45 (8), 40 (1993).

3. H. Hahn and R. S. Averback, J. Am. Ceram. Soc. 74, 2918 (1991).

4. M. Jain and T. Christman, Acta Metall. Mater. 42, 1901 (1994).

5. M. F. Ashby and R. A. Verrall, Acta Metall. 21, 149 (1973).

6. R. C. Gifkins, J. Mater. Sci. 13, 1926 (1978).

7. T. G. Langdon, Metals Forum 4, 14 (1981).

8. K. Tsuzaki, H. Matsuyama, M. Nagao, and T. Maki, Mat. Trans. JIM 31, 983 (1990).

9. S. Erbel, Met. Technol. 6, 482 (1979).

10. I. Saunders and J. Nutting, Metal Sc. 18, 571 (1984).

11. R. Z. Valiev, E. V. Kozlov, Y. F. Ivanov, J. Lian, A. A. Nazarov, and B. Baudelet, Acta Metall. 42, 2467 (1994). 